\title{
ABORDANDO A RELAÇÃO DE EULER ATRAVÉS DO OBJETO DE APRENDIZAGEM UMA PLETORA DE POLIEDROS: UM ESTUDO DE CASO COM ALUNOS DO TERCEIRO ANO DO ENSINO MÉDIO
}

\author{
Viviane Beatriz Hummes ${ }^{1}$ \\ Adriana Breda ${ }^{2}$
}

\section{Resumo}

Este trabalho objetiva apresentar alguns resultados em relação ao processo de aprendizagem, a partir de uma perspectiva vygotskyniana, da relação de Euler através do uso do objeto de aprendizagem Uma Pletora de Poliedros. Para isso, foi realizado um estudo de caso com dez alunos de uma turma de $3^{\circ}$ ano do Ensino Médio em uma escola da rede pública de Porto Alegre. Os dados foram coletados por meio de dois questionários: um identificando as idéias prévias e o outro, o que os alunos aprenderam após a aplicação do dispositivo virtual. A partir da análise dos dados, concluiu-se que, embora, os alunos expressassem, inicialmente, os poliedros como figuras planas, após o uso do software, eles conseguiram estabelecer a relação entre faces, arestas e vértices das figuras, compreendendo que estas são figuras tridimensionais.

Palavras-chave: relação de Euler, Uma Pletora de Poliedros, Vygotsky, aprendizagem.

\section{APROACHING EULER'S RELATION THROUGH THE LEARNING OBJECT A PLETHORA OF POLYHEDRA: A CASE STUDY WITH STUDENTS OF THE THIRD GRADE OF HIGH SCHOOL}

\begin{abstract}
The aim of this work is to present results regarding the learning process, through a Vygotskian perspective, of Euler's relation through the learning object A Plethora of Polyhedra. To do so, a case study has been performed with ten students of a third grade high school class of a public school in Porto Alegre. The data have been colected from two questionnaires : one identifying the prior ideas and the other what the students have learnt after the use of the virtual device. From the data analysis, it was concluded that although the students expressed, initially, the polyhedra as flat figures, after the use of the software they managed to establish the relationship between the faces, edges and vertices of the figures, perceiving that they are three-dimensional figures.
\end{abstract}

Keywords: Euler's relation, A Plethora of Polyhedra, Vygotsky, learning

\footnotetext{
${ }^{1}$ Graduada em Matemática pela UFRGS e mestranda no Programa de Pós-Graduação em Ensino de Matemática/UFRGS. E-mail: vivihummes@gmail.com

${ }^{2}$ Graduada em Matemática pela UFRGS, mestra em Educação em Ciências e Matemática pela PUCRS, profes sora no Cap-UFRGS. E-mail: adriana.breda@gmail.com
} 


\section{Introdução}

Segundo Moraes (1998), para que possamos criar novos ambientes de aprendizagem que atendam às novas necessidades da sociedade contemporânea, é necessário focalizar no indivíduo singular, o indivíduo único que traz consigo inteligências múltiplas, aberto a diferentes instrumentos de aprendizagem, dotado de inúmeras possibilidades de resolver problemas, em suma, àquele que se deixa levar pelo que está em seu entorno sócio cultural. Nesse sentido, reconhecemos a importância de não tratar o processo de ensino e aprendizagem apenas como uma mera transmissão de conteúdos, mas sim, tratá-lo de forma na qual o aluno aprenda através do estabelecimento de relações e que ele possa atribuir significado às coisas. É por esse motivo que pensamos em um currículo para as aulas de matemática no qual estejam contemplados e sejam valorizadas a interatividade, a conectividade, a interdependência e a autonomia do educando e acreditamos que os novos ambientes de aprendizagem informatizados possibilitam novas estratégias de ensino-aprendizagem, pois, segundo Moraes (1998) são instrumentos capazes de aumentar a motivação, a concentração e a autonomia, permitindo ao aluno a manipulação de sua própria representação e a organização do seu próprio conhecimento.

Nesse sentido, pensamos em uma atividade para as aulas de geometria que pudesse dar conta de todos os aspectos apresentados acima de tal forma que o aluno pudesse interagir com o objeto de aprendizagem Uma Pletora de Poliedros ${ }^{3}$ e pudesse construir com autonomia a relação que se estabelece entre faces, vértices e arestas de poliedros, de tal forma que, ele pudesse compreender o que é um poliedro. O objeto de aprendizagem é um software interativo, disponibilizado no site: Conteúdos digitais para $o$ ensino e aprendizagem de matemática e estatística do Instituto de Matemática da Universidade Federal Fluminense (IM-UFF), e faz parte do Banco Internacional de Objetos Educacionais do Ministério da Educação e Cultura (MEC). O objeto possibilita o exercício de visualização espacial, identificação, comparação e análise de atributos geométricos e topológicos dos poliedros.

$\mathrm{Na}$ sequência desse texto, apresentamos alguns aspectos referentes à fundamentação teórica, ao objeto virtual de aprendizagem Uma Pletora de Poliedros, ao processo metodológico de coleta e da análise dos dados e, finalmente, os resultados obtidos a partir de nosso processo investigativo.

\section{Fundamentação teórica}

O uso do computador na escola, não serve somente como uma máquina pronta para transmissão do saber. Conforme aponta Valente (2008), a grande utilização desse instrumento é o pacto interacional que ele, juntamente com o aprendiz constituem juntos, sendo a internet uma ótima rede que disponibiliza diversos recursos e instrumentos pedagógicos. Nesse sentido, para (Nicola, Rodrigues, 2011, p.02) “[...] objetos de aprendizagem são recursos disponibilizados pela internet com o objetivo de promover o conhecimento e que recebem diferentes definições, dependendo do autor que o estiver usando."

Pierre Levy (1999), afirma que as tecnologias digitais fornecem novas formas de acesso à informação, pois suas memórias são dinâmicas e podem ser partilhadas em um grande número de indivíduos, constituindo um potencial de inteligência

\footnotetext{
3 Disponível em: BORTOLOSSI, H. J. Uma Pletora de Poliedros, 2008. Disponível em:
} http://www.uff.br/cdme/pdp/. Acesso em: 10 out. 2011. 
conjunta/coletiva entre os grupos humanos e é nesse sentido que compactuamos com as idéias de Vygotsky (1987), pois a concepção de desenvolvimento humano para este teórico, acontece a partir das relações sociais que o indivíduo estabelece durante a sua vida. Nesse sentido, em uma perspectiva vygotskyniana, o processo de ensino e aprendizagem está diretamente relacionado às interações e relações sociais que o indivíduo estabelece com e nos diferentes contextos socioculturais durante toda sua trajetória de vida.

Para Wertsch, Del Río e Álvarez (1997), as ferramentas culturais fornecem, por um lado, a ligação ou a ponte entre as ações concretas conduzidas por indivíduos e grupos, e por outro, contextos culturais, institucionais e históricos.

\begin{abstract}
Portanto, as habilidades cognitivas e as formas de estruturar o pensamento do indivíduo não são determinadas por fatores congênitos. São, isto sim, resultado das atividades praticadas de acordo com os hábitos sociais da cultura em que o indivíduo se desenvolve. Consequentemente, a história da sociedade na qual a criança se desenvolve e a história pessoaldesta criança são fatores cruciais que vão determinar sua forma de pensar. Neste processo de desenvolvimento cognitivo, a linguagem tem papel crucial na determinação de como a criança vai aprender a pensar, uma vez que formas avançadas de pensamento são trans mitidas à criança através de palavras. (Vygotsky, 1987, p.04).
\end{abstract}

Nesse contexto, compreendemos que o uso da ferramenta internet faz parte do contexto cultural e social das crianças e dos jovens da atualidade e, é nesse sentido, que acreditamos na importância da utilização de objetos virtuais de aprendizagem nas aulas de matemática, visto que, a constituição do conhecimento do educando depende das inter-relações que este estabelece com o concreto que está em seu entorno e com a linguagem que ele externaliza a partir daquilo que apreendeu.

Em um ambiente educacional, o aluno, ao trabalhar com recursos computacionais, é orientado pelo professor e, nesse sentido, o professor assume o papel de mediador da aprendizagem. Essa relação entre o aluno e uma pessoa mais experiente disposta a orientá-lo está ligada a idéia de Zona de Desenvolvimento Proximal, (Vygotsky,1987), isto é, é a diferença entre a capacidade do aluno aprender sozinho e a capacidade de ele aprender com o auxilio de uma pessoa que já possui algum conhecimento ou alguma experiência em determinado assunto. "Zona de desenvolvimento próximo, por sua vez, abrange todas as funções e atividades que a criança ou o aluno consegue desempenhar apenas se houver ajuda de alguém." (Vygotsky, 1987, p.4).

A partir do exposto, acreditamos que o aluno, ao utilizar o objeto de aprendizagem Uma Pletora de Poliedros, ao ser mediado pelo professor, desenvolve autonomia e capacidade de alcançar os objetivos propostos por determinada atividade e assim, aprender determinados conteúdos e definições que envolvam a geometria espacial, em especial, os que tangem alguns sólidos geométricos, neste caso, os poliedros.

\title{
3. Aspectos Metodológicos
}

A abordagem metodológica que escolhemos para o trabalho foi qualitativa. Segundo Günther (2006), a pesquisa qualitativa está baseada no estudo das relações como compreensão e não apenas como transmissão de dados. Nesse tipo de abordagem, o mais importante é compreender o processo de como as coisas acontecem e é nesse sentido que o método deve se adequar ao objeto de estudo, contemplando todas as variáveis como sendo importantes. 
Para a realização dessa pesquisa, fizemos um estudo de caso com dez alunos do terceiro ano do ensino médio em uma escola de rede pública de Porto Alegre. Para Ponte (1994), um estudo de caso se refere a um estudo de uma entidade definida e, nesse sentido, caracteriza-se a uma análise muito particular, uma situação específica e única em diversos aspectos

O investigador não pretende modificar a situação, mas compreendê-la tal como ela é. Para isso apóia-se numa "descrição grossa" (thick description), is to é, factual, literal, sistemática e tanto quanto possível completa do seu objeto de estudo. No entanto, [...] Pode ter igualmente um profundo alcance analítico, interrogando a situação, confrontando-a com outras situações já conhecidas e com as teorias existentes.(Ponte, 1994, p. 2-3).

Para realização do estudo de caso, aplicamos um questionário inicial de perguntas abertas para verificarmos quais as concepções que os alunos têm em relação aos poliedros e em quais lugares poderiam ser encontrados. Após isso, apresentamos para os alunos o objeto de aprendizagem Uma Pletora de Poliedros, um software interativo, que permite visualizar e manipular vários tipos de poliedros (platônicos, de Arquimedes, prismas, etc.). Nesse ambiente, diversas operações geométricas são disponibilizadas para os usuários, como, por exemplo, a planificação do poliedro, a exibição das faces, arestas e vértices. Todas essas ferramentas possibilitam o exercício da visualização espacial: identificação, comparação e o estabelecimento de relações entre os elementos que constituem e classificam os poliedros.

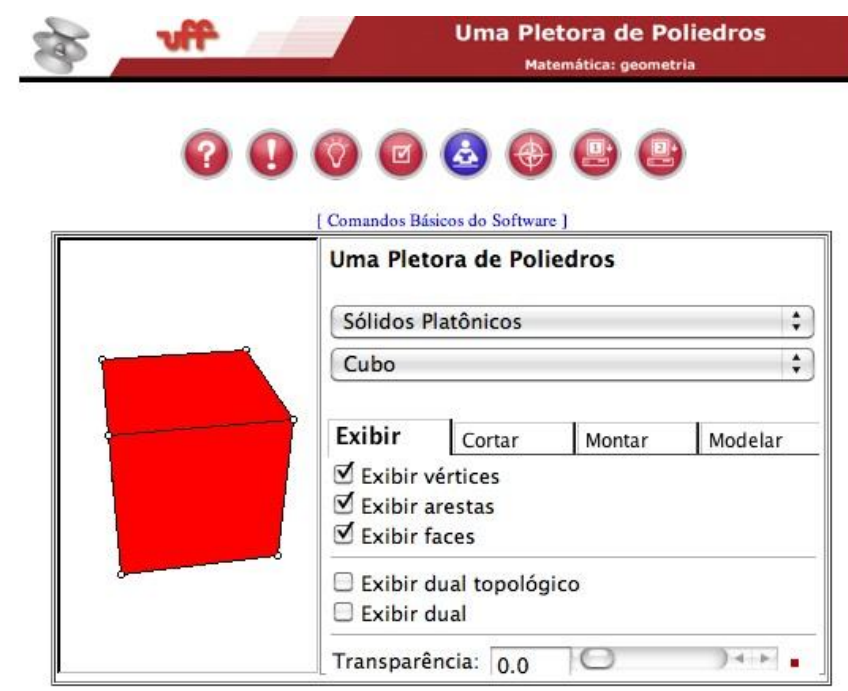

Figura 1 - Layout do software Uma Pletora de Poliedros

Em seguida aplicamos uma atividade guiada, proposta pelo próprio software Uma Pletora de Poliedros, na qual consistiu em verificar o número de vértices, faces e arestas dos poliedros: tetraedro, cubo, tetraedro truncado, pirâmide quadrada, prisma reto de base triangular, dodecaedro e icosaedro. 


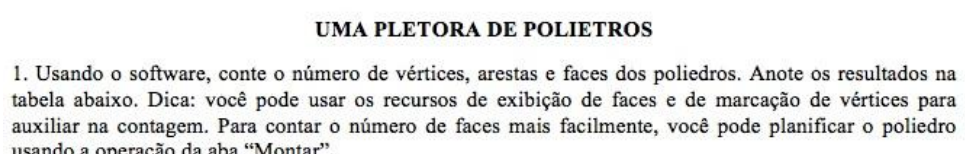
usando a operação da aba "Montar".

\begin{tabular}{|c|c|c|c|c|c|}
\hline Categoria & Poliedro & $\begin{array}{c}\text { Número de } \\
\text { Vértices (V) }\end{array}$ & $\begin{array}{c}\text { Número de } \\
\text { Faces (F) }\end{array}$ & $\begin{array}{c}\text { Número de } \\
\text { Arestas (A) }\end{array}$ & $\begin{array}{c}\text { Valor de } \\
\text { V + F - A }\end{array}$ \\
\hline Sólidos Platônicos & Tetraedro & & & & \\
\hline Sólidos Platônicos & Cubo & & & & \\
\hline $\begin{array}{c}\text { Sólidos } \\
\text { Arquimedianos }\end{array}$ & $\begin{array}{c}\text { Tetraedro } \\
\text { Truncado }\end{array}$ & & & & \\
\hline Sólidos de Johnson & $\begin{array}{c}\text { Pirâmide } \\
\text { Quadrada }\end{array}$ & & & & \\
\hline Prismas & $\begin{array}{c}\text { Reto de Base } \\
\text { Triângular }\end{array}$ & & & & \\
\hline Sólidos Platônicos & Dodecaedro & & & & \\
\hline Sólidos Platônicos & Icosaedro & & & & \\
\hline
\end{tabular}

Figura 2 - Atividade guiada proposta pelo software Uma Pletora de Poliedros

Finalizamos aplicando um questionário que tomou como suporte as seguintes questões: O que você aprendeu sobre os poliedros? Quais foram às dificuldades encontradas durante a utilização de Uma Pletora de Poliedros? Quais foram as dificuldades encontradas para obter a Relação de Euler? O que você aprendeu com a relação de Euler?

Para análise das narrativas apresentadas pelos alunos, utilizamos a metodologia Análise Textual Discursiva de Moraes e Galiazzi (2008), que consiste na unitarização das narrativas, categorização das mesmas e a construção de um metatexto. Este último, juntamente com um aporte teórico consistente, tem como característica apresentar fidedignidade científica aos dados coletados. No próximo capítulo apresentamos os resultados obtidos a partir da análise das respostas dos questionários e do desenvolvimento dos alunos em relação à atividade guiada sobre a relação de Euler.

\section{A compreensão da Relação de Euler a partir do uso do objeto de aprendizagem Uma Pletora de Poliedros}

Para desenvolvermos este capítulo, partiremos da análise de algumas respostas que surgiram por parte dos alunos em relação à primeira questão do questionário aplicado no início da atividade: o que você sabe sobre poliedros? No nosso entendimento, a maioria das respostas evidenciou que, para os alunos, a definição de poliedros estaria associada a noção de figuras planas, isto é, poliedros seriam figuras em duas dimensões e não figuras espaciais. A maioria dos alunos não expressou a diferença entre algo que tem volume e algo que está representado no espaço bidimensional. Por exemplo, para eles, o cubo seria uma espécie de quadrado, assim como, a pirâmide seria um tipo de triângulo. Para o aluno " $\mathrm{H}$ " poliedros "[...] são objetos em forma de desenhos geométricos, tais como quadrado, triângulo, círculo." (Aluno H). Para o aluno "D", "Poliedros cercam objetos compactos como o cubo em que o mesmo é sólido e tem o formato geométrico, até mesmo uma pirâmide em que tem uma forma de triângulo." (Aluno D).

Acreditamos, segundo as idéias de Vygotsky, que a concepção a respeito de poliedros apresentada por alguns alunos, pode ser classificada como uma concepção espontânea e esta, segundo Martins (1999), é construída pelo educando a partir de suas 
relações diárias, é aquilo que o educando "pensa que é". Entretanto, mesmo que a concepção esteja incorreta, ela não deve ser caracterizada como obstáculo à aprendizagem, e sim, deve ser encarada como a porta de entrada para a efetivação da aprendizagem do conceito científico.

Compreendemos também, que o aluno até pode pensar em um poliedro como uma figura que apresenta volume, mas, no momento em que ele expressa aquilo que ele pensa ser um poliedro, ele só consegue expressá-lo como se este fosse uma figura plana. Para Vigotsky (1987), esta é uma questão que está diretamente relacionada à linguagem. É através da linguagem que são expressados e internalizados os significados constituídos através da vivência e das interações sociais que a criança ou o adolescente estabelece durante sua trajetória. As preferências, concordâncias e os antagonismos são expressões dos significados sociais que eles estabelecem. Nesse sentido, a linguagem não é apenas a expressão daquilo que a criança aprendeu, mas sim, o pensamento e a linguagem apresentam uma inter-relação, isto é, um proporciona recursos ao outro, em outras palavras: pode-se dizer que pensamento e linguagem estabelecem uma relação biunívoca.

Uma palavra não se refere a um objeto simples, mas a um grupo ou a uma classe de objetos e, por conseguinte, cada palavra é já de si uma generalização. A generalização é um ato verbal de pensamento e reflete a realidade duma forma totalmente diferente da sensação e da percepção. (Vygotsky, 1987, p.10).

Após responder o questionário inicial, os alunos iniciaram a manipulação do objeto Uma Pletora de Poliedros afim de preencher a tabela com o número de vértices $(\mathrm{V})$, faces $(\mathrm{F})$, arestas (A) e o valor de $\mathrm{V}+\mathrm{F}-\mathrm{A}$. Para auxiliar o processo de contagem, foi utilizado o recurso de exibição de arestas e vértices, conforme figuras 3 e 4 .

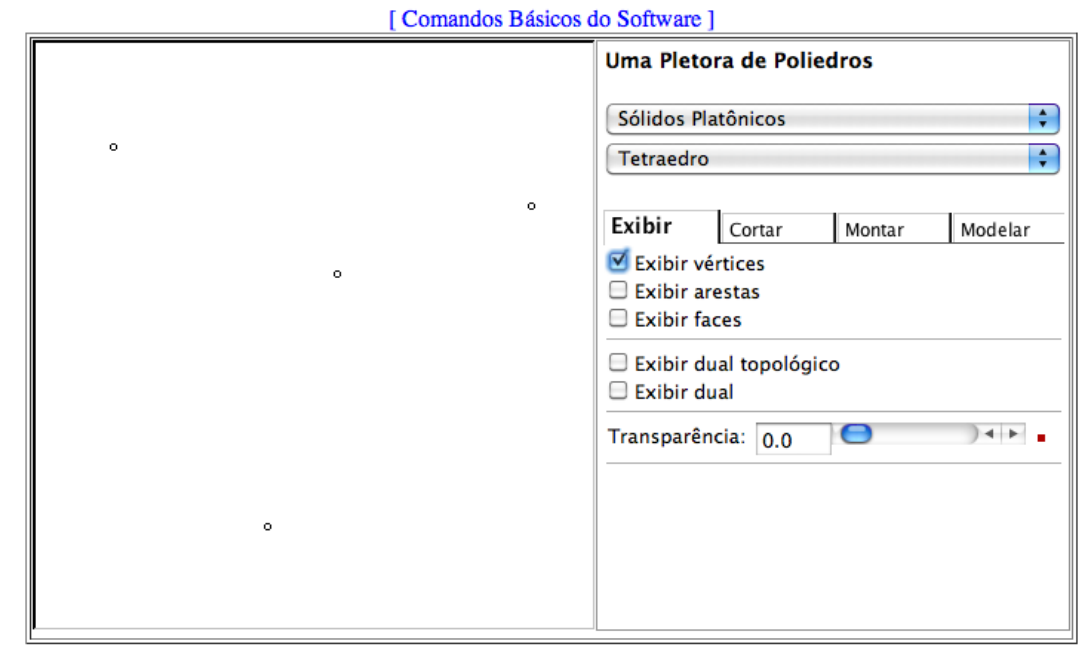

Figura 3 - Visualização dos vértices do tetraedro a partir do ícone exibir vértices 


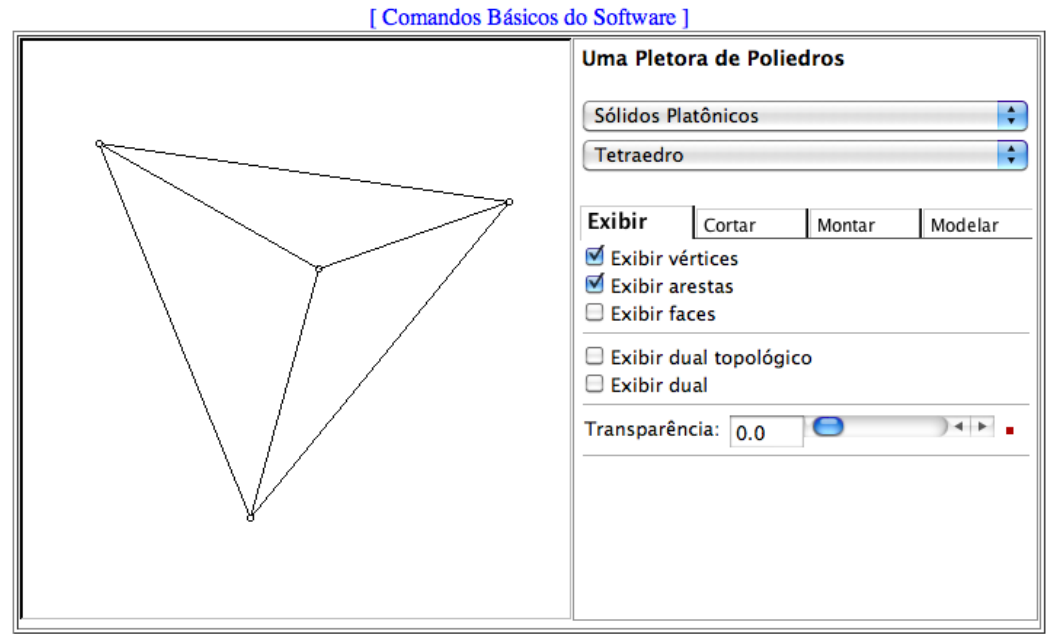

Figura 4 - Visualização das arestas e dos vértices do tetraedro a partir dos ícones: exibir vértices e exibir arestas

Para contar o número de faces, os alunos utilizaram o recurso "Montar" do software, que possibilita a planificação do sólido, conforme figura 5.

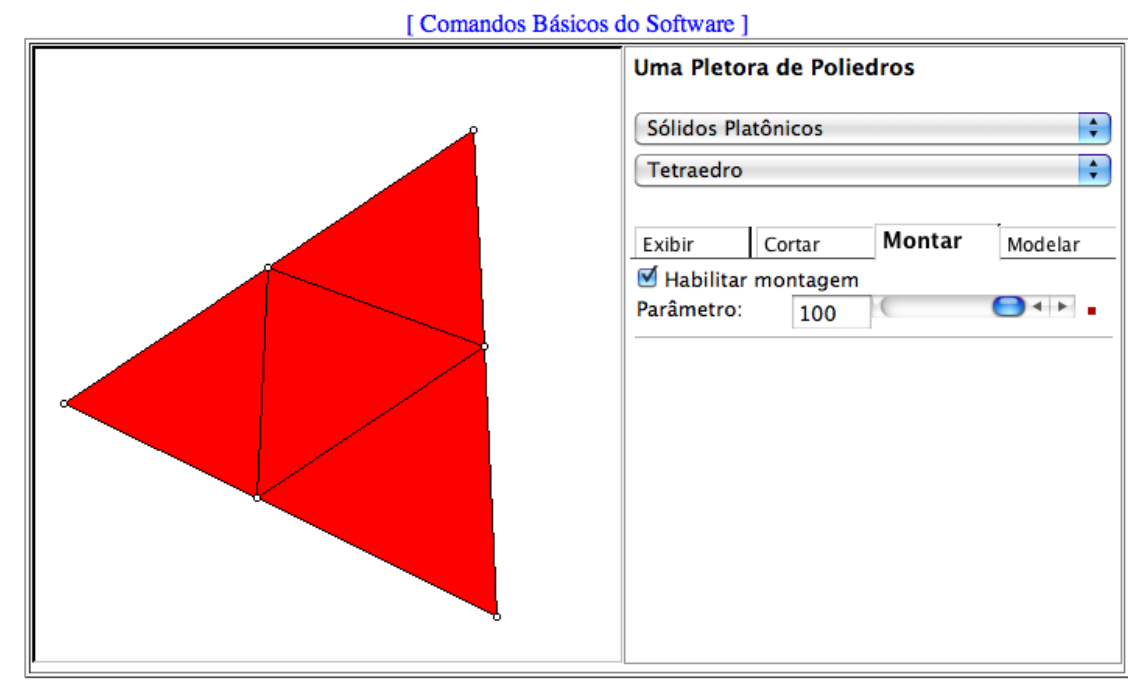

Figura 5 - Visualização do tetraedro a partir do ícone Habilitar Montagem

A estratégia de contar o número de faces, arestas e vértices, a partir da exibição no dispositivo virtual, foi facilmente desempenhada para os sólidos Platônicos: tetraedro e cubo; para o sólido Arquimediano: tetraedro truncado; para o sólido de Johnson: pirâmide quadrada; e para o prisma reto de base triangular. Contudo, não foi trivial para os sólidos Platônicos: dodecaedro e icosaedro, pois, estes poliedros possuem grande número de arestas. Ver figura 6. 


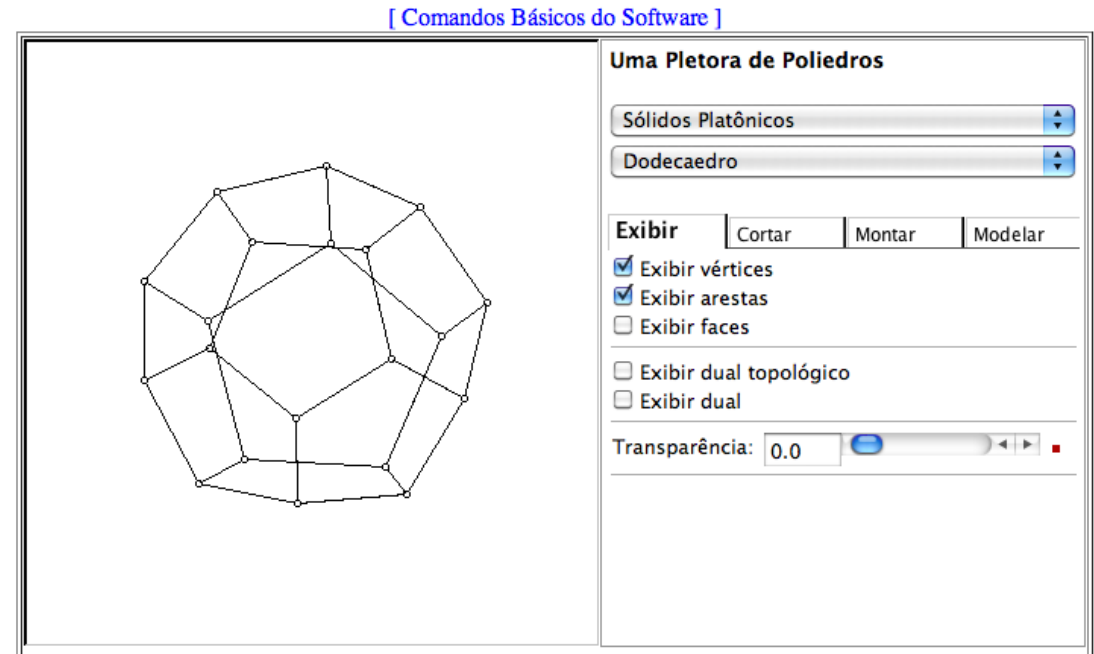

Figura 6 - Visualização das arestas e dos vértices do dodecaedro a partir dos ícones: exibir vértices e exibir arestas

As dificuldades apresentadas para a contagem das arestas do dodecaedro e do icosaedro, ficaram evidentes nas respostas de uma das perguntas que faziam parte do questionário final: quais foram as dificuldades encontradas durante a utilização do software Uma Pletora de Poliedros? O aluno "A" respondeu: "Fica difícil de contar o número de vértices e faces de figuras muito grandes" (Aluno A). Já, o aluno "D" respondeu: "Sólidos como muitas faces são impossíveis de contar apenas olhando superficialmente sua imagem projetada no computador" (Aluno D). O aluno "I" expressou: "A maior dificuldade foi para encontrar o número de arestas." (Aluno I).

Em pouco tempo, a maior parte dos alunos havia percebido que a operação número de vértices $(\mathrm{V})$ mais faces $(\mathrm{F})$ menos arestas $(\mathrm{A})$ resultava sempre no número dois, $\mathrm{V}+\mathrm{F}-\mathrm{A}=2$. Essa relação ficou clara nas respostas apresentadas a partir da pergunta: o que você aprendeu sobre poliedros? O aluno "D" respondeu: "Somando os vértices, as faces e diminuindo as arestas vai ter 2 como resultado." (Aluno D). Já, o aluno "A" comentou: "Que na Relação de Euler os poliedros são sempre constantes. Número de vértices, faces e arestas na relação o resultado sempre será 2.” (Aluno A).

De posse disso, alguns alunos apresentaram a estratégia verbalizada pelo aluno "B": "Se eu conheço o número de faces, o número de vértices e sei que $\mathrm{V}+\mathrm{F}-\mathrm{A}=2$ então tenho como encontrar o valor de arestas. [...] No caso do dodecaedro: faces são doze (12), pois é dodecaedro, contei o número de vértices que são vinte (20), então faces mais vértices dá 32, então A só pode ser 30." (Aluno B).

Levando em conta as narrativas expressadas acima, compreendemos que, conforme Martins (1999), a partir do momento em que o educando está em contato com o objeto de aprendizagem dentro de um espaço escolar, espera-se que o conceito que anteriormente considerado espontâneo, adquira um grau de abstração que tem por objetivo, segundo Vygotsky, definir o conceito científico.

\footnotetext{
A aprendizagem dos conceitos científicos adquiridos via mediação cultural, que se dá na e pela interação com professores e colegas, apóia-se em um conjunto previamente desenvolvido de conhecimentos originários das experiências diárias da criança. Esse conhecimento, espontaneamente adquirido, passa a ser o mediador da aprendizagem de novos saberes. (Martins, 1999, p.119).
}

Concordando com as ideias acima, compreendemos que Uma Pletora de Poliedros auxiliou os sujeitos investigados, pois através da manipulação dos poliedros 
disponibilizados pelo software e o auxilio do professor como mediador, os alunos que até então não sabiam definir um poliedro como uma figura de três dimensões, aprenderam que entre esses sólidos, há uma particularidade, isto é, o número de vértices somado com o número de faces subtraído do número de arestas resulta na constante igual a dois.

\section{Considerações finais}

Neste trabalho investigamos quais as concepções prévias dos alunos em relação ao que seriam poliedros e, a partir disso, desenvolvemos uma atividade guiada com auxílio do objeto de aprendizagem Uma Pletora de Poliedros no intuito de compreender como o aluno, ao interagir com tal ferramenta, estabelece relações entre os elementos que constituem os poliedros, e assim, possibilitar a eles a compreensão de que poliedros são figuras tridimensionais que apresentam uma relação muito particular, isto é, $\mathrm{V}+\mathrm{F}-\mathrm{A}=2$.

A utilização desse objeto virtual de aprendizagem contribuiu, de maneira significativa, para a construção e compreensão da relação de Euler, possibilitando o alcance do objetivo proposto, isto é, a compreensão de que poliedros são figuras tridimensionais que possuem uma relação entre suas faces, vértice e arestas. Nesse sentido, acreditamos que objetos de aprendizagem podem auxiliar de maneira significativa a construção do conhecimento e que estes são excelentes recursos para o entendimento de conteúdos complexos, como por exemplo, a visualização de arestas, vértices e faces dos poliedros.

Com este estudo percebemos que o uso de objetos de aprendizagem nas aulas de geometria espacial possibilitam ao aluno a autonomia necessária para gerenciar seu aprendizado. A utilização do objeto Uma Pletora de Poliedros pode ser expandida para exploração de diversos conteúdos e atividades que envolvem a geometria espacial, como, por exemplo, trabalhar área de prismas a partir de sua planificação, classificar poliedros, explorar o conceito de dualidade topológica, entre outros.

\section{Referências Bibliogáficas}

BORTOLOSSI, H. J. Uma Pletora de Poliedros, 2008. Disponível em: http://www.uff.br/cdme/pdp/. Acesso em: 10 out. 2011.

GUINTHER, H. Pesquisa qualitativa versus pesquisa quantitativa: esta é a questão?. Psicologia: Teoria e Pesquisa (UnB. Impresso), v. 22, p. 201-209, 2006.

LÉVY, P. Cibercultura. São Paulo: Editora 34, 1999.

MARTINS, J. C. Vygotski e o papel das interações sociais na sala de aula: reconhecer e desvendar o mundo. Idéias, v. 28, p. 111-122, 1999.

MORAES, M. C. Novas tendências para o uso das tecnologias de informação na educação. Edutecnet: Textos, 1998. Disponível em http://edutec.net/Textos/Alia/MISC/edmcand2.htm. Acesso em 13 de out. de 2011.

MORAES, R.; GALIAZZI, M. C. Análise Textual Discursiva. Ijui: Editora Unijui, 2008, 223 p. 
NICOLA, L. B. ; RODRIGUES, A . Objetos de aprendizagem como potencializadores no estudo da Biologia. RENOTE. Revista Novas Tecnologias na Educação, v.9, no 1 , jul. 2011.

PONTE, J. P. O estudo de caso na investigação em educação matemática. Quadrante, vol. 3(1), 1994, 3-18.

VALENTE, J. A. Por que o computador na educação? .In: SALGADO, M. U. C.; AMARAL, A. L. Tecnologia na Educação: ensinando e aprendendo com as TIC: guia do cursista. Brasilia: Ministério da Educação, Secretaria de Educação à Distancia, 2008. p. $193-210$.

VYGOTSKY, L. S. Pensamento e Linguagem. São Paulo. Martins Fontes, 1987.

WERTSCH, J. DEL RÍO, P. ÁLVAREZ, A. La mente sociocultural. Madrid. Fundación Infancia y aprendizaje Carretera de Canillas, 1997. 